\title{
BROWNFIELDS E SUAS CONSEQUÊNCIAS: \\ UM CASO ESPECÍFICO DA OPERAÇÃO URBANA BAIRROS DO TAMANDUATEÍ
}

\author{
BROWNFIELDS AND ITS CONSEQUENCES: \\ A PARTICULAR CASE OF THE URBAN OPERATION OF \\ TAMANDUATEÍ DISTRICTS
}

\author{
Vania Cristiane Flores Salinas \\ Mestranda em Paisagem e Ambiente na Faculdade de São Paulo - FAU/USP, especialista em \\ habitação social e gestão ambiental, graduada em Arquitetura e Urbanismo no \\ Uni centro Belas Artes de SP. \\ e-mail: flores.salinasvaniac@gmail.com
}

\begin{abstract}
RESUMO
A questão da contaminação dos solos é crucial para um planejamento urbano sustentável, principalmente nas cidades que tiveram sua história marcada pelo desenvolvimento industrial como São Paulo. Os problemas da contaminação do solo vai além do empobrecimento do mesmo e de seus componentes, sendo algo que afeta o meio ambiente e toda a cadeia alimentar e produtiva.

Neste artigo será tratada uma área dentro da operação urbana Bairros do Tamanduateí que conflita com as propostas trazidas pelo projeto de Lei da Operação Urbana, uma vez que ele não define diretrizes para como será tratada a questão da contaminação, além disso, discute-se a necessidade de entender a rapidez com que se deve trabalhar estas áreas para que elas não sejam ocupadas irregularmente o que pode agravar ainda mais os danos oriundos da industrialização.
\end{abstract}

Palavras-chave: Água contaminada; Contaminação do solo; Remediação; Descontaminação; Operação Urbana Bairros do Tamanduateí. 


\begin{abstract}
The matter of soil contamination is crucial for sustainable urban planning, especially in cities that had the history marked by industrial development like São Paulo. Soil contamination problems are beyond its own impoverishment and of its components. It is something that affects the environment and the entire food and production chains.

This article focuses an area inside the Urban Operation of Tamanduatei District, which conflicts with the proposals brought by the Urban Operation Law since it does not set guidelines for how to deal with the matter of contamination. Furthermore, it is discussed the need to understand how fast these areas must be improved so that they are not illegally occupied, what can aggravate even more the damages occurred due to the industrialization process.
\end{abstract}

Keywords: Polluted Water; Soil Contamination; Remediation; Decontamination; Operation Urban of Tamanduateí District.

\title{
INTRODUÇÃO
}

Em artigo anterior publicado pela própria autora (Contaminação do solo em São Paulo: O caso da Operação Urbana Bairros do Tamanduateí) foram levantadas algumas das dificuldades que a Municipalidade têm em solucionar os problemas de contaminação na região para a qual estão sendo elaborados estudos para a implantação da Operação Urbana Consorciada Bairros do Tamanduateí. A região possui forte predominância industrial que faz parte da sua história, sendo problemático que muitas das indústrias do local foram desativadas em uma época em que pouco se sabia dos riscos que as atividades industriais poderiam trazer para a saúde e para o meio ambiente por conta do passivo ambiental que estas geravam.

Atualmente existem vários países que trabalham através de planos e programas as áreas contaminadas, criando fundos para o saneamento das mesmas. Países como Inglaterra, França e Alemanha, que possuem grande parte do seu desenvolvimento através do crescimento industrial, são os pioneiros nas ações de descontaminação. 
Nacionalmente, embora seja bastante recente a discussão sobre a contaminação dos solos, existem legislações que auxiliam a combater tais problemas. A população também tem atualmente um conhecimento maior das consequências da contaminação de áreas urbanas e seu cadastro está disponível no site da CETESB e na Secretaria Municipal do Verde e do Meio Ambiente - SMVA, aberto à população. Importante ressaltar que no próprio site da CETESB encontram-se listadas doze áreas classificadas como críticas no que diz respeito a sua contaminação, sendo duas delas áreas em que foram construídos empreendimentos habitacionais de HIS (Habitação de Interesse Social) pela COHAB em solo contaminado.

O destaque dado a estas áreas deve-se à alta demanda de moradia na cidade de São Paulo que aumentou nos últimos anos, levando o poder público a ter grande dificuldade em encontrar terrenos vazios aptos para moradia, descartando muitas vezes terrenos com qualquer tipo de passivo ambiental. O problema nesse sentido é que estes terrenos quando localizados em pontos estratégicos da cidade e ociosos por muito tempo acabam sendo alvo de ocupações irregulares que não só expõem seus moradores aos contaminantes, mas que devido às ligações irregulares, descarte inadequado de lixo ou acúmulo do mesmo por catadores, pode piorar a situação do local e dos seus moradores.

O presente artigo se baseará nos estudos da OUC Bairros do Tambaduateí e em parte do estudo do Programa Integration denominado como setor Henry Ford.

\section{ENTENDENDO A HISTÓRIA QUE LEVOU AO ATUAL PROBLEMA}

A necessidade de entender os problemas da cidade para a remediação destes torna necessário o estudo da história do local. Este aprofundamento na história da cidade de São Paulo ajuda a entender melhor quando começam os problemas no planejamento urbano que culminaram nas consequências hoje vivenciadas.

A história da cidade de São Paulo nos indica como e porque a cidade que antigamente era uma cidade de chácaras passou a ser uma das maiores cidades da América Latina e com um polo industrial tão forte, conforme exposto por F. SANTOS:

"Nas imediações do rio Tamanduateí, antes do processo de adensamento populacional que marcou o final do século XIX, havia um cinturão de chácaras, fazendas e sítios que muitas vezes viviam independentemente da cidade. Ao longo do século XIX, especialmente após a fundação da Faculdade de 
Direito, o rio começou a ser incorporado pela cidade, paralelo ao processo de parcelamento das áreas adjacentes, que também iam sendo incorporadas pela cidade. Mas foi efetivamente após a ligação férrea que a área começou a sofrer intervenções mais drásticas no sentido de englobá-la ao conjunto da cidade. Vale destacar, que em meio a estas mudanças, suas funções também iam se alterando." (Santos, 2006).

Um dos motivos principais para a expansão de São Paulo foi o fato da cidade ser a porta de entrada para as cidades do interior, o que tornou a cidade polo distribuidor, enquanto Santos se tornou o porto onde os produtos eram recebidos. Com esta nova estrutura de distribuição, a cidade de São Paulo começa a ganhar espaço e destaque e surge outra forma de geração de renda, a venda de lotes e aluguel de quartos para imigrantes. Anos mais tarde, com a alteração da dinâmica económica da cidade e a construção da ferrovia próxima aos cursos d'agua, inicia-se a instalação de indústrias em locais próximos aos córregos e à ferrovia, uma vez que a proximidade com o córrego barateava o custo do terreno pelo longo histórico de alagamentos e de problemas de saúde, já que se tratavam de terrenos baixos e úmidos. A localização das indústrias acima citada atrai novo contingente de trabalhadores que aos poucos se estabelecem no entorno do seu local de trabalho. Atualmente estes são os bairros Brás e Mooca.

Em 1890 após o médico Sr. Caetano Campos enfatizar os problemas que ele enfrentara com diversos pacientes provenientes da várzea do Carmo se abre um debate sobre a melhoria na qualidade de vida e sobre a prevenção de infecções com foco na retificação dos rios, que se iniciou em 1896 com a retificação do rio Tamanduateí, só concluída dezoito anos depois. A retificação do córrego chegou a melhorar parcialmente não só os problemas decorrentes das águas estagnadas como infecções e doenças, mas também o problema das enchentes. Contudo, ela iniciou outro processo problemático para a cidade, qual seja, a expulsão da população que utilizava o córrego como fonte de renda e como área de lazer.

A Figura 1 a seguir ilustra as etapas de retificação do córrego do Tamanduateí: sendo a primeira em 1848, quando fora desviado somente o trecho das "sete voltas" onde hoje encontra-se a rua 25 de março e a intervenção final em 1896, com o desvio do curso do córrego e sua retificação. 


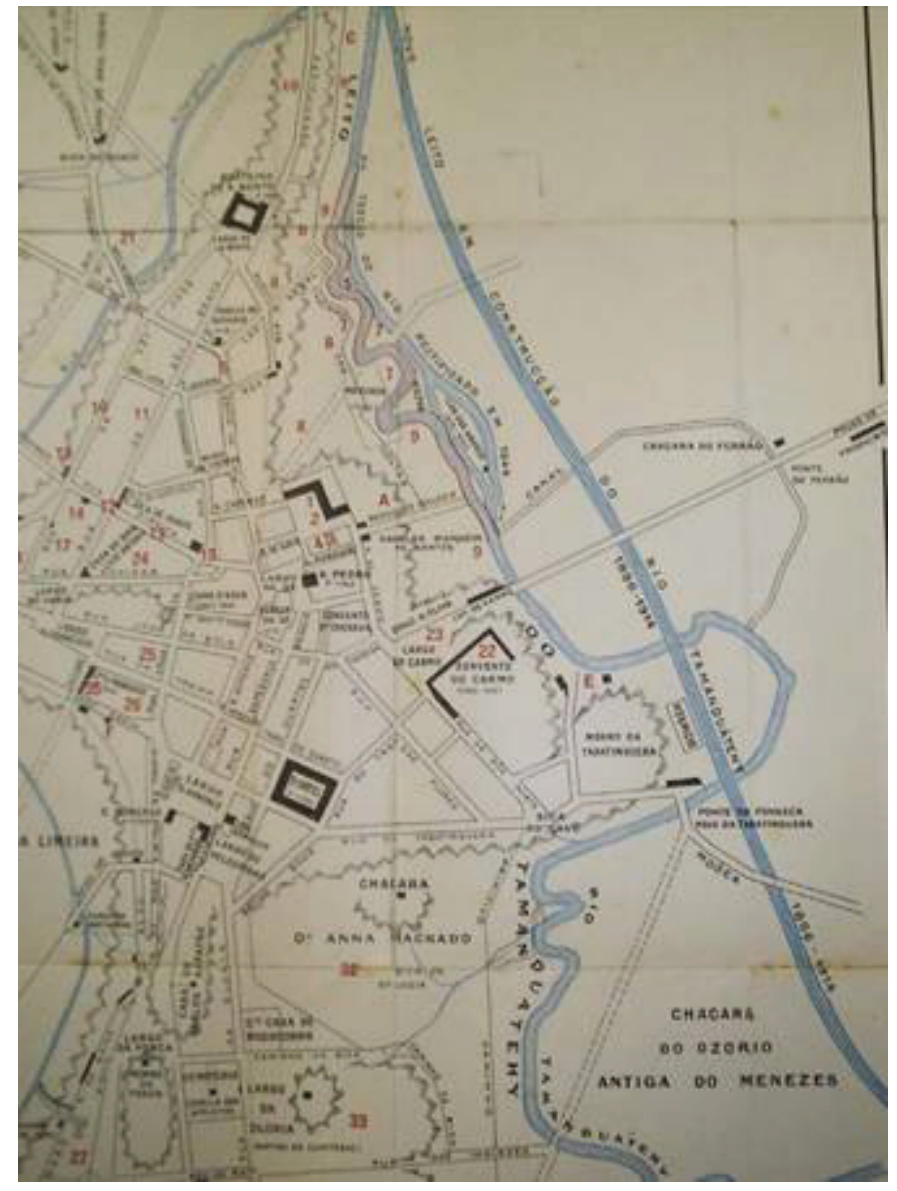

Figura 1 - Mapa identificando faseamento das obras no Tamanduateí.

Fonte: Domando as águas -

Fabio Santos, 2006

Uma vez feita a retificação do Córrego do Tamanduateí e construída a Av. do Estado, não foi possível precisar a propriedade das áreas adjacentes ao melhoramento viário1. Sem um proprietário determinado os terrenos se tornaram espaço sem função e alvo de ocupações irregulares.

Isto pode ser observado a partir da análise de uma das quadras fiscais afetada pela canalização do córrego, a qual ocasionou a divisão de lotes em pequenos trechos, ora da Prefeitura de São Paulo, ora de propriedade particular.

1 O Decreto-Lei 121/41 aprovou um novo traçado para o Canal do Tamanduateí. Este Decreto Lei sofreu duas alterações, a Lei 4724/55 que modifica o plano e a 4881/56 que modificou o traçado. Em 1973 através da Lei 7892/73 é aprovado o plano de alargamento da Av. do Estado alterando parcialmente o alinhamento estabelecido pelo Decreto-Lei, já em 1977 surge a Lei 8529 que aprova o plano de fixação da Av. do Estado e altera parcialmente o decreto lei, e no seu Art. $2^{\circ}$ cola a seguinte situação: "Os imóveis atingidos pelo plano ora aprovado serão oportunamente declarados de utilidade pública, para efeito de desapropriação". 
A Figura 3 mostra em verde tracejado a área considerada como área pública pelo Mapa Digital da Cidade, porém esta informação difere da informação levantada através dos contribuintes ilustrada na Figura 2.

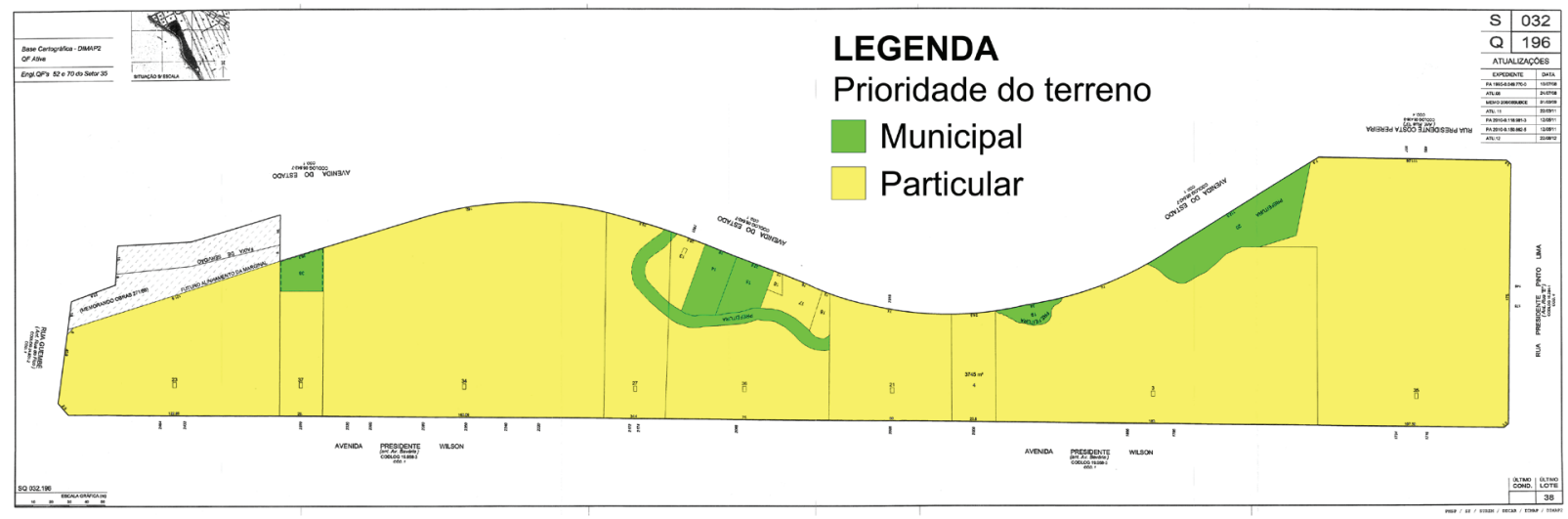

Figura 2 - Identificação da propriedade dos lotes

Fonte: SQL e dados de autenticidade e validade do histórico da Edificação.

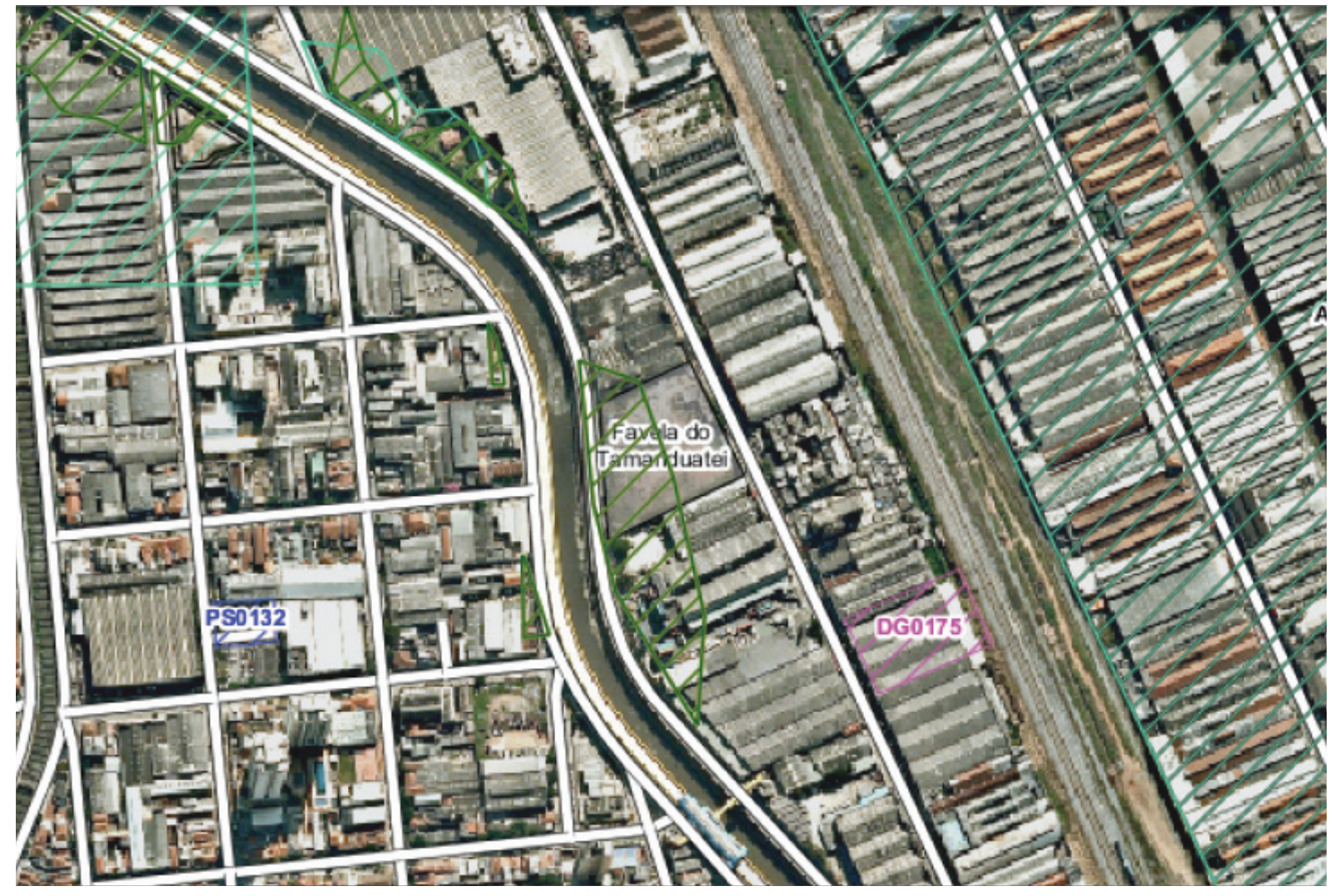

Figura 3 - Identificação de área pública pelo MDC

Fonte: Mapa Digital da Cidade - MDC 


\section{SETOR HENRY FORD - IPIRANGA, UM LOCAL DE VULNERABILIDADE}

O setor localiza-se na sub-bacia hidrográfica Parque da Mooca e segundo os dados levantados pelo EIA, tem parte do seu território delimitado em uma Unidade Geotécnica de Aluvião (1al) e outra em uma Unidade de Sedimentos da Formação São Paulo e Correlatos terciários.

A Figura 4 nos mostra como era a região em 1930. No local onde se encontrava o córrego hoje estão instaladas várias indústrias e algumas favelas. Esta era uma região de várzea que abrigava meandros do córrego do Tamanduateí.

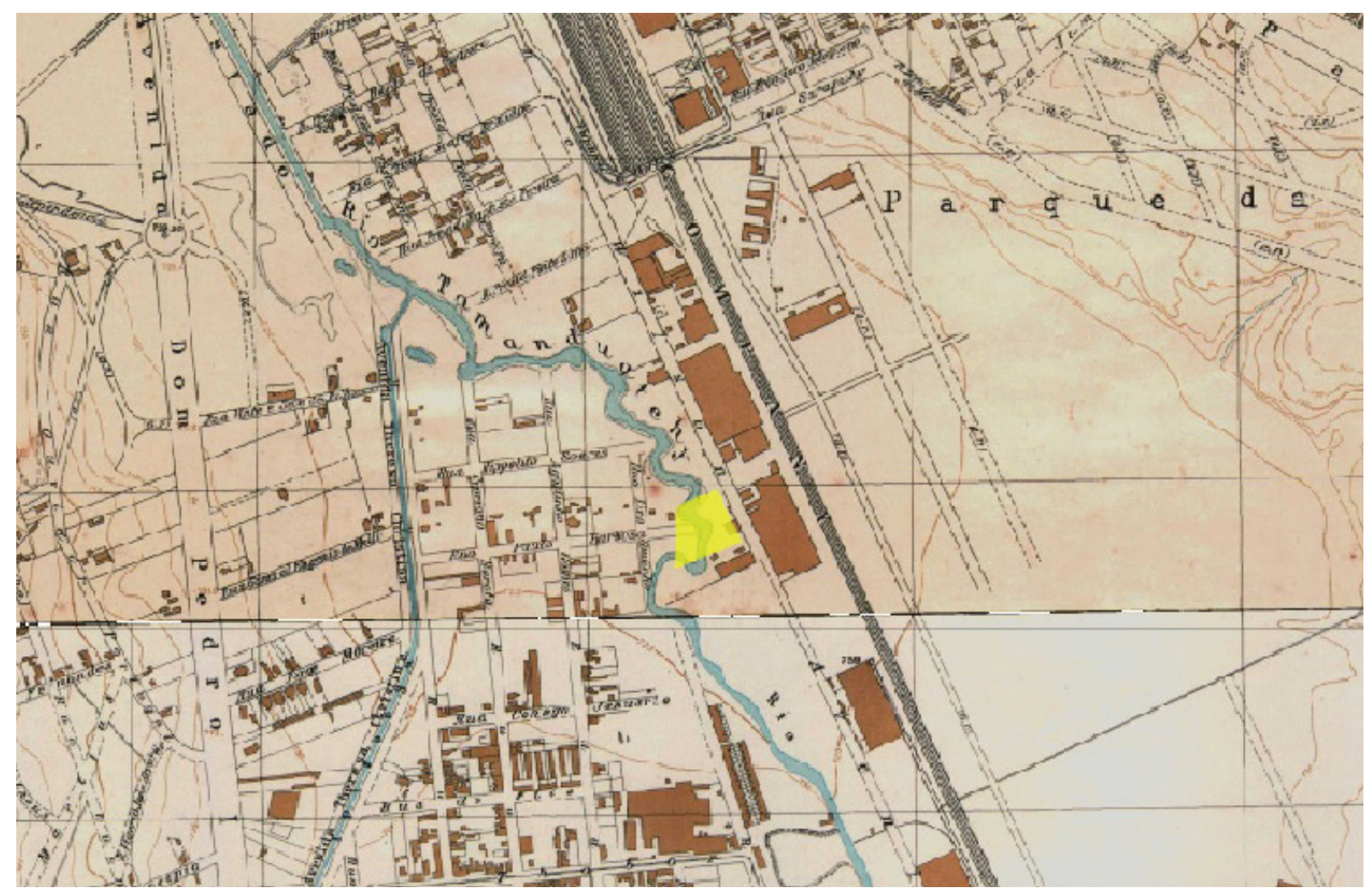

Figura 4 - Sara Brasil 1930 com sobreposição da favela.

Fonte: Mapa Digital da Cidade - MDC

A porção de território mais próxima ao córrego localizada na Figura 5 identificada como 1al mostra um território mais frágil, conformada por depósitos aluviais, e possui um nível de lençol freático próximo à superfície ou aflorante. Estes locais podem gerar diversos problemas, mas os que mais interessam ao presente trabalho são os seguintes; enchentes, solapamento, recalque das fundações e assoreamento das várzeas entre outras dificuldades apresentadas no próprio estudo. 


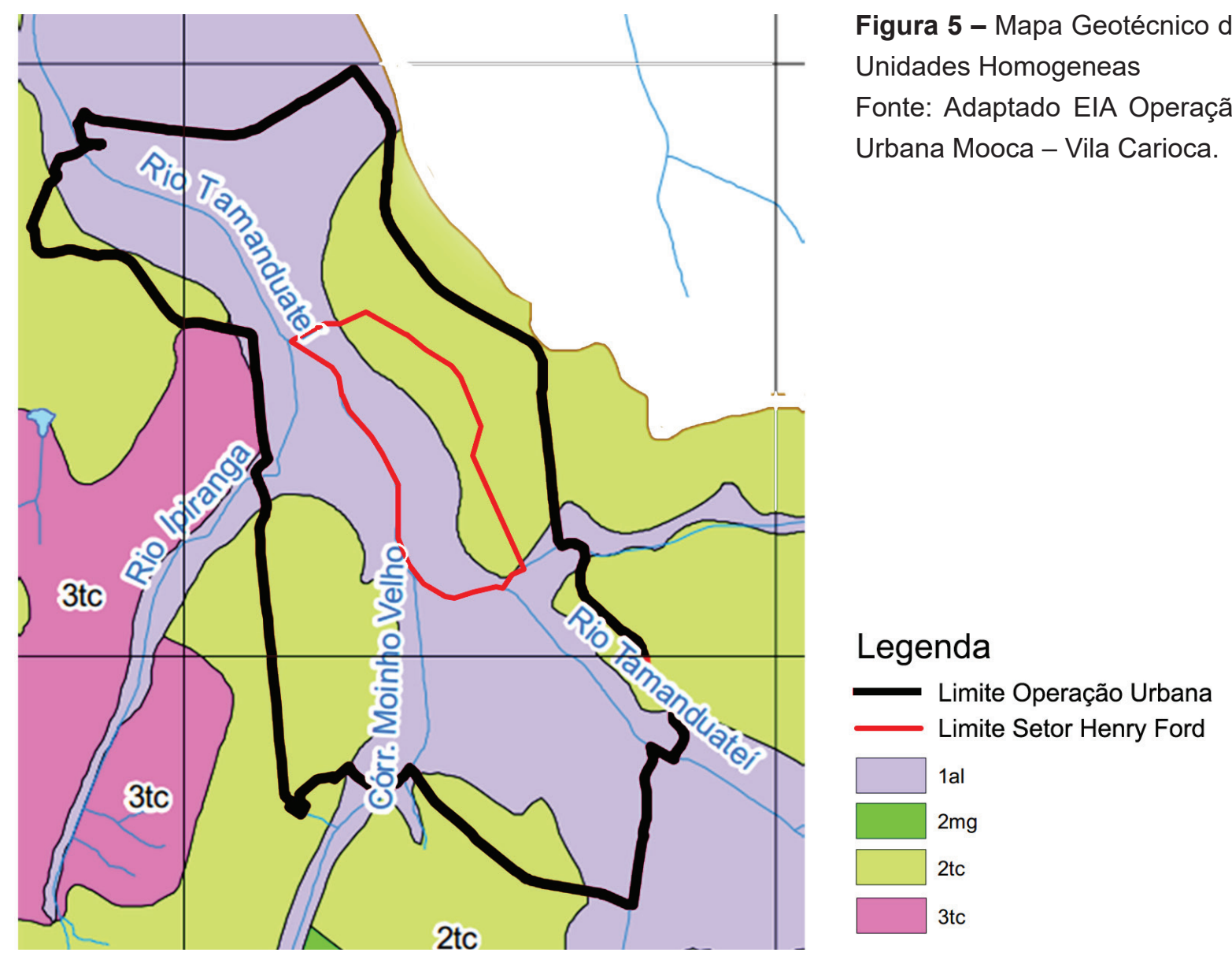

O EIA identifica o Setor Henry Ford como o setor de maior vulnerabilidade social dentro da Operação Urbana. A proposta indica alguns terrenos como ZEIS-3 com a finalidade de construir moradias no local para sujeitos com distintas faixas de salários.

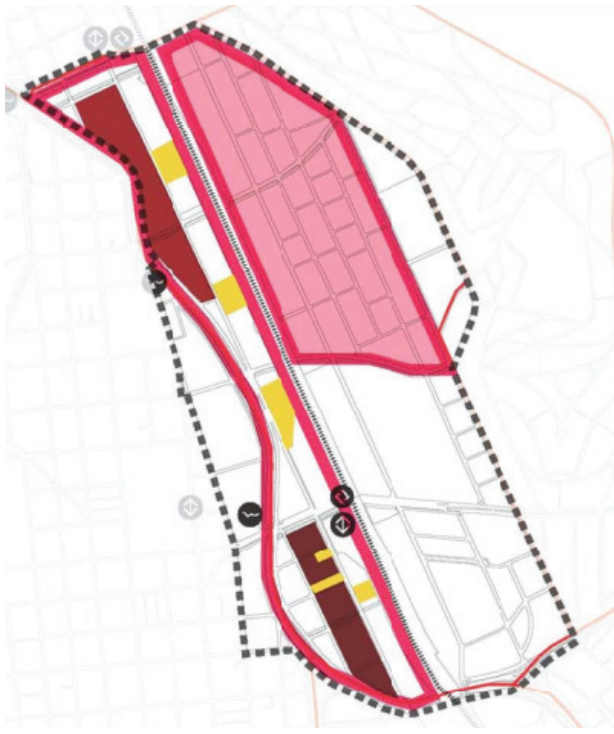

Figura 6 - Identificação das ZEIS-3 e bens

a serem preservados.

Fonte: EIA Mooca - Vila Carioca, CMVC.

(1)

Perímetro Trecho 01

Perímetro Trecho 02

Imóveis a serem indicados de interesse de preservação ZEIS 3 

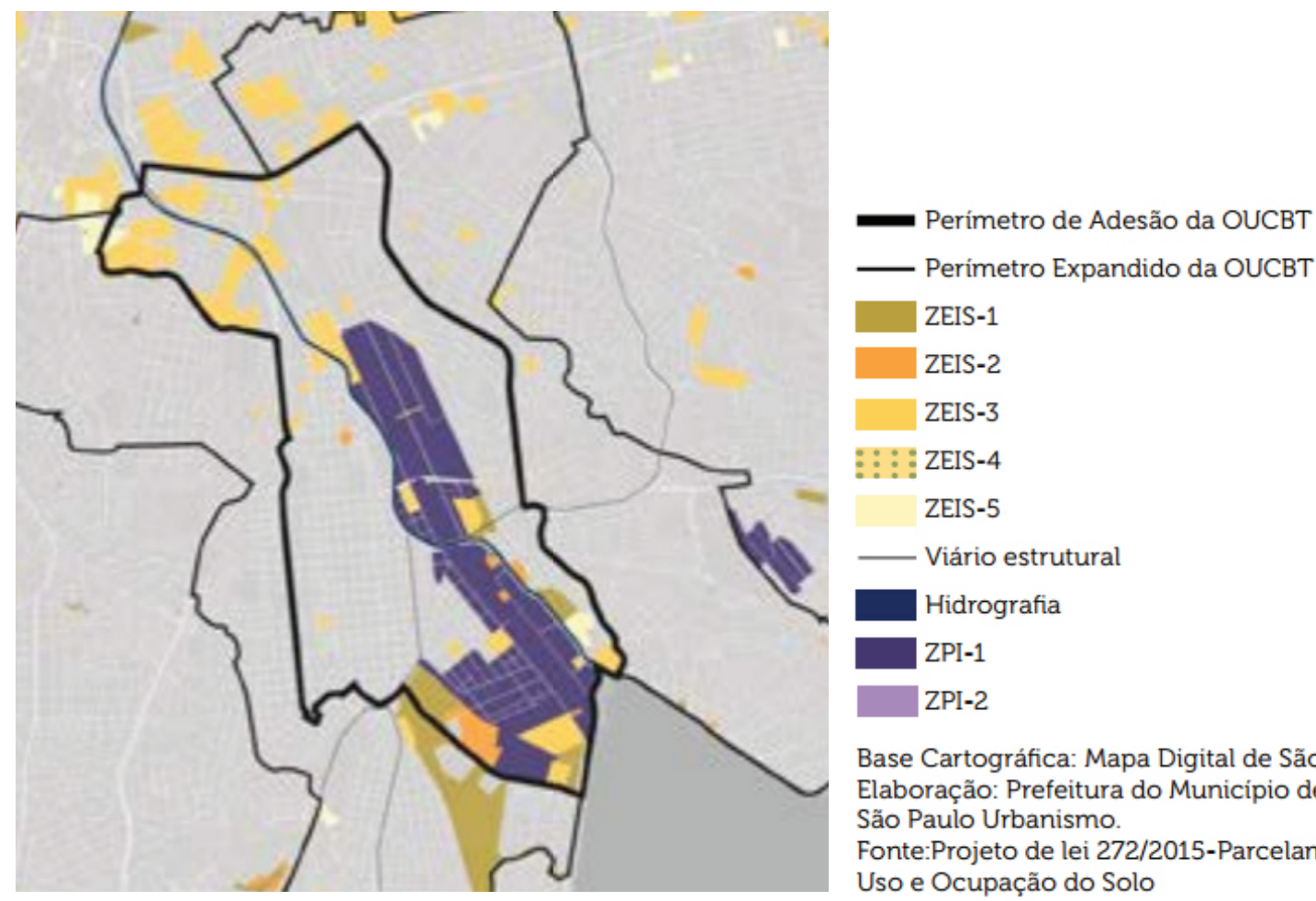

Base Cartográfica: Mapa Digital de São Paulo, 2004 Elaboração: Prefeitura do Município de São Paulo. São Paulo Urbanismo.

Fonte:Projeto de lei 272/2015-Parcelamento,

Uso e Ocupação do Solo

Figura 7 - Identificação das ZEIS-3 na Minuta do Projeto de Lei.

Fonte: Minuta do Projeto de Lei da Operação Urbana Bairros do Tamanduateí.

Observa-se nos trechos acima indicados que as áreas identificadas pelo EIA (ver Figura 9) e também pelos estudos elaborados pelo programa Integration (Figura 8) como contaminadas ou com um alto potencial de contaminação foram classificadas como ZEIS pelo EIA (Figura 6), sendo que uma destas foi mantida como tal pela Minuta de projeto de Lei da Operação Urbana em questão (Figura 7).

Um dos motivos que geralmente influencia os planejadores a definir uma área como ZEIS é o uso e ocupação que está sendo dado para determinado local no momento dos estudos. A região escolhida como ZEIS-3 tem uma porção do seu território ocupado por uma favela, contudo, as imagens que veremos a seguir nos mostrarão que tal porção de território possui uma grande probabilidade de estar contaminado. 


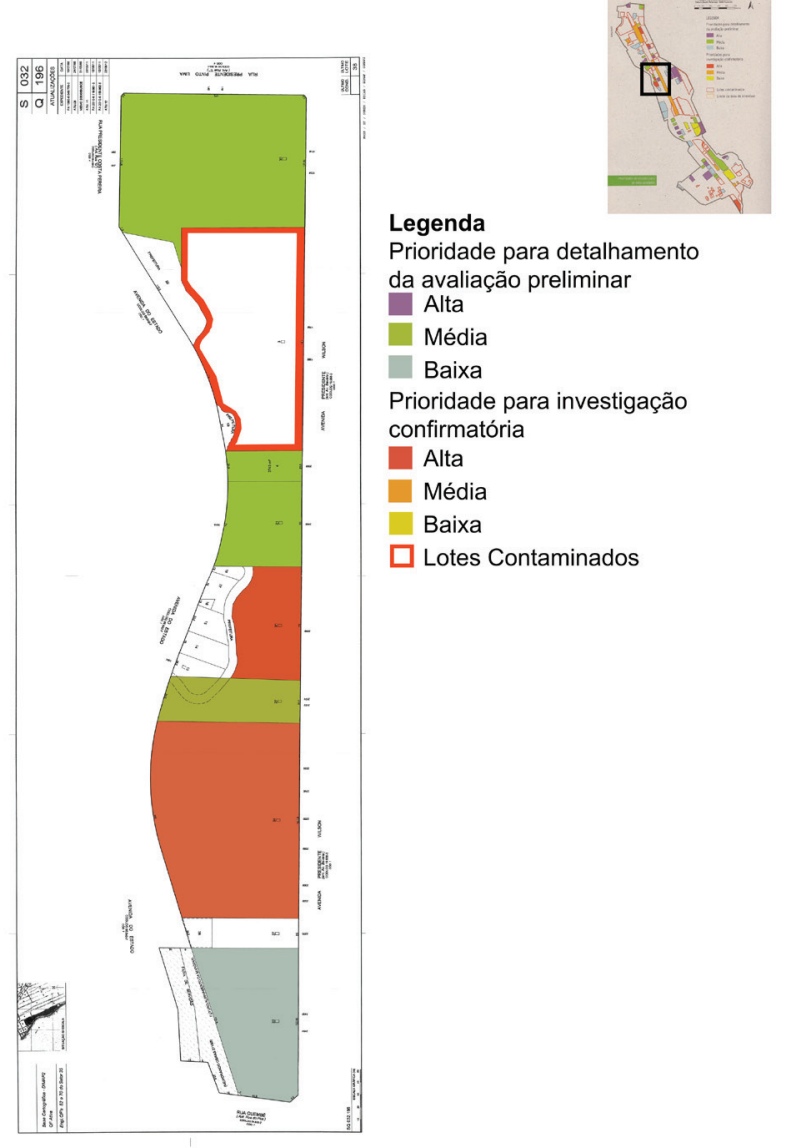

Figura 8 - Prioridade de estudos par aos lotes avaliados pelo Programa Integration.

Fonte: Adaptado programa Integration e SQL do Mapa Digital da Cidade de São Paulo - MDC

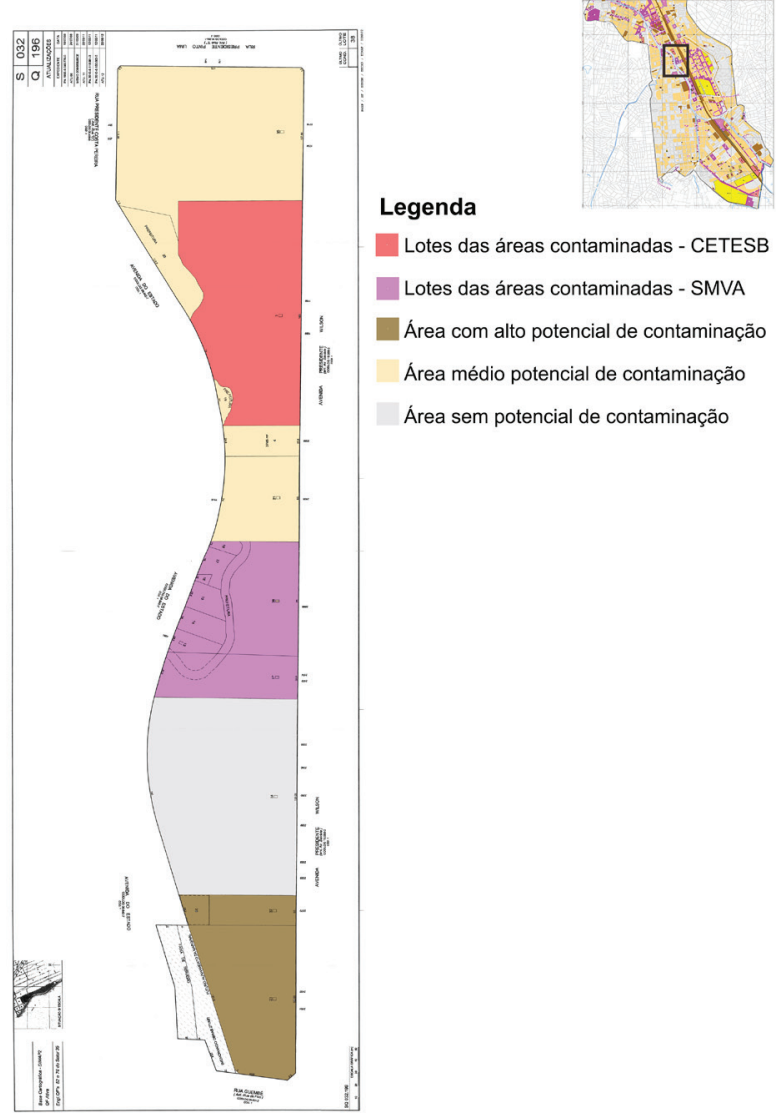

Figura 9 - Estudo de áreas contaminadas no Setor 032, Quadra 196

Fonte: Adaptado EIA Bairros do Tamanduateí CMVC e SQL do Mapa Digital da Cidade de São Paulo - MDC

Os estudos acima citados, embora com algumas divergências - o que pode ser devido à data da sua elaboração - identificam o setor com um alto potencial de contaminação. A análise dos dados abertos aos munícipes do Grupo Tecnico Permanente de Áreas Contaminadas GTAC/SMVA e pela CETESB confirma pelo menos uma das áreas acima indicadas como contaminada (Figura 10). 


\begin{tabular}{|c|c|c|c|c|c|c|}
\hline SQL: & \multicolumn{3}{|l|}{ 032.196.0003-4; } & \multirow{2}{*}{\multicolumn{2}{|c|}{$\begin{array}{l}\text { Zoneamento: } \\
\text { Classificação: }\end{array}$}} & Zona Especial de Interesse Social (ZEIS-3) \\
\hline Endereço: & \multicolumn{3}{|c|}{ Av. Presidente Wilson, 1786 e 1866} & & & Em Processo de Monitoramento para Reabilitação \\
\hline CEP: & \multicolumn{3}{|l|}{ 03107-001 } & \multirow{3}{*}{\multicolumn{2}{|c|}{ Contaminante: }} & \multirow{3}{*}{$\begin{array}{l}\text { Fenóis } \\
\text { Metais } \\
\text { Solventes Aromáticos } \\
\text { Solventes Aromáticos Halogenados }\end{array}$} \\
\hline Distrito: & \multicolumn{3}{|l|}{ Ipiranga } & & & \\
\hline \multirow[t]{10}{*}{ Subpref.: } & \multicolumn{3}{|l|}{ Ipiranga - SPIP } & & & \\
\hline & & & & \multicolumn{2}{|c|}{ Restrição: } & Água Subterrânea \\
\hline & & & & \multicolumn{2}{|c|}{ Intervenção: } & Bombeamento e tratamento \\
\hline & & & & \multicolumn{3}{|c|}{$\begin{array}{l}\text { Esta área também está cadastrada na Listagem de Áreas Contaminadas e Reabilitadas do } \\
\text { Estado de São Paulo (CETESB - Dez/2011) }\end{array}$} \\
\hline & \multicolumn{3}{|c|}{ Vértices*: } & & & \\
\hline & 1 & $336.312 \mathrm{E}$ & $7.392 .599 \mathrm{~N}$ & 2 & $336.388 \mathrm{E}$ & $7.392 .436 \mathrm{~N}$ \\
\hline & & $336.350 \mathrm{E}$ & $7.392 .417 \mathrm{~N}$ & 4 & $336.333 \mathrm{E}$ & $7.392 .436 \mathrm{~N}$ \\
\hline & & $336.313 \mathrm{E}$ & $7.392 .436 \mathrm{~N}$ & 6 & $336.280 \mathrm{E}$ & $7.392 .468 \mathrm{~N}$ \\
\hline & & $336.282 \mathrm{E}$ & $7.392 .484 \mathrm{~N}$ & 8 & $336.267 \mathrm{E}$ & $7.392 .522 \mathrm{~N}$ \\
\hline & & $336.222 \mathrm{E}$ & $7.392 .557 \mathrm{~N}$ & 10 & $336.312 \mathrm{E}$ & $7.392 .599 \mathrm{~N}$ \\
\hline
\end{tabular}

Figura 10 - Ficha de área contaminada da Secretaria do Meio Ambiente Fonte: Cadastro de Áreas Contaminadas DECONT/GTAC/SMVA

Ressalta-se com esta pesquisa o fato de que a pluma de contaminação encontrada neste terreno não se limita ao lote contaminado, podendo ter se difundido para o próprio córrego e talvez para áreas capazes de fechar a chamada rota de contaminação.

Dada à proximidade do lençol freático com a superfície, como identificado anteriormente, a contaminação aqui tratada alcança as águas subterrâneas do local, o que auxilia na rapidez de sua propagação já que ela se desloca conjuntamente com a água subterrânea.

O atual terreno em questão está sendo tratado para se remediar seu pasivo ambienal.

\section{A VULNERABILIDADE DEVIDO A FALTA DE CONHECIMENTO}

Segundo informações da Secretaria Municipal de Habitação, a favela identificada em área potencialmente contaminada, localizada na Av. Presidente Wilson, é oriunda de uma reintegração de posse da Favela Presidente Wilson II ocorrida em 2010 que se instalou nas estruturas de um prédio em construção da Polícia Civil do Estado de São Paulo (Figura 11).

Embora ambas as favelas se encontrassem localizadas no meio de dois eixos de transporte de alta relevância para a cidade - CPTM Mooca e Ipiranga e a Av. do Estado - o transporte para a região continua sendo precário, já que os dois eixos criam barreiras para a mobilidade dos moradores do local. 
Em visita na área não foi possível identificar comércios ou serviços de suporte para as moradias na sua proximidade. Contudo não foi possível estabelecer contato com os moradores para acessar a favela, logo, não se pode afirmar que eles não possuem dentro da favela locais de serviços e comércios que deem suporte às moradias.

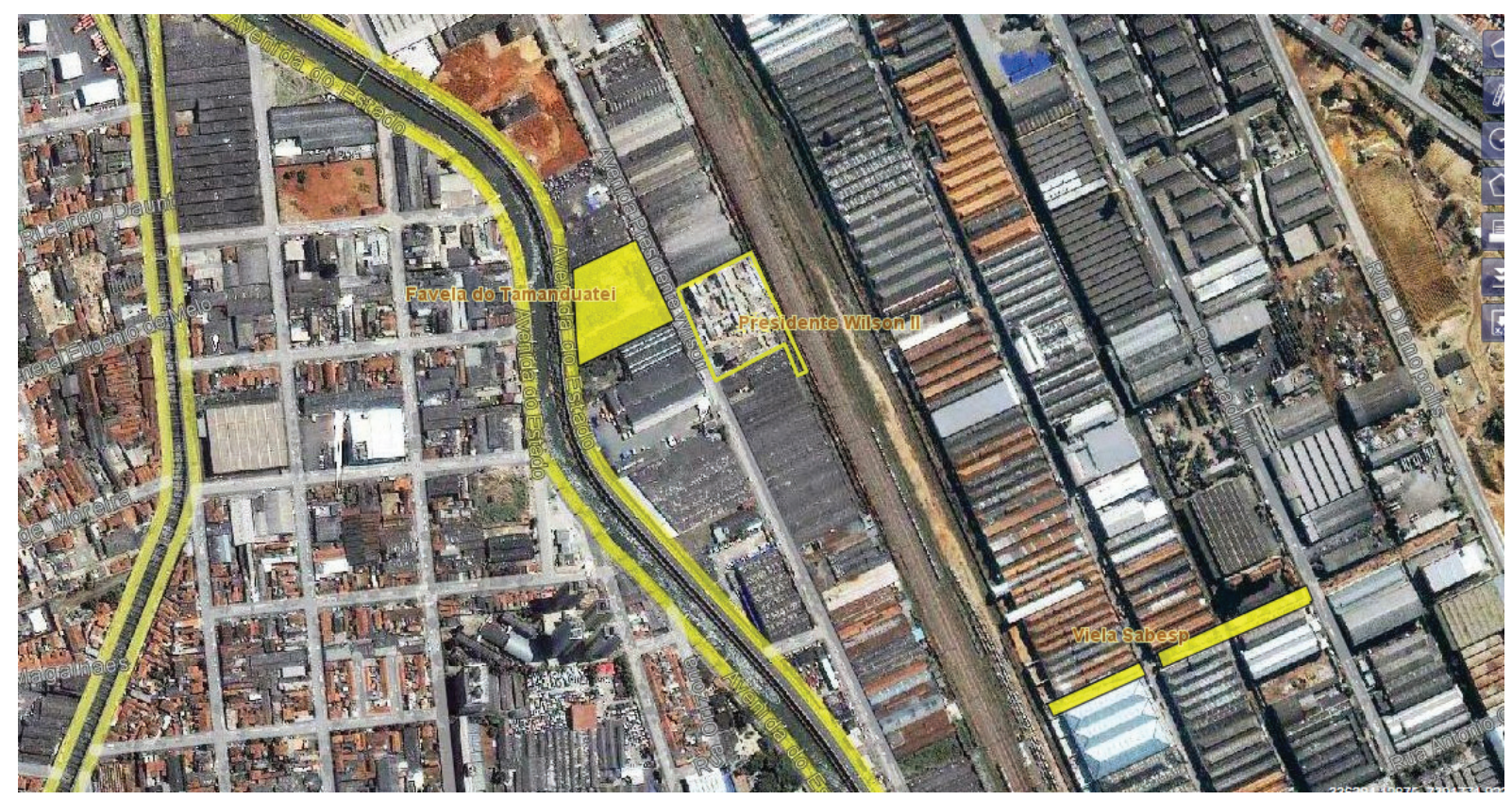

Figura 11 - Sobreposição de layers identificando as favelas. Fonte: Adaptado Habisp Plus.

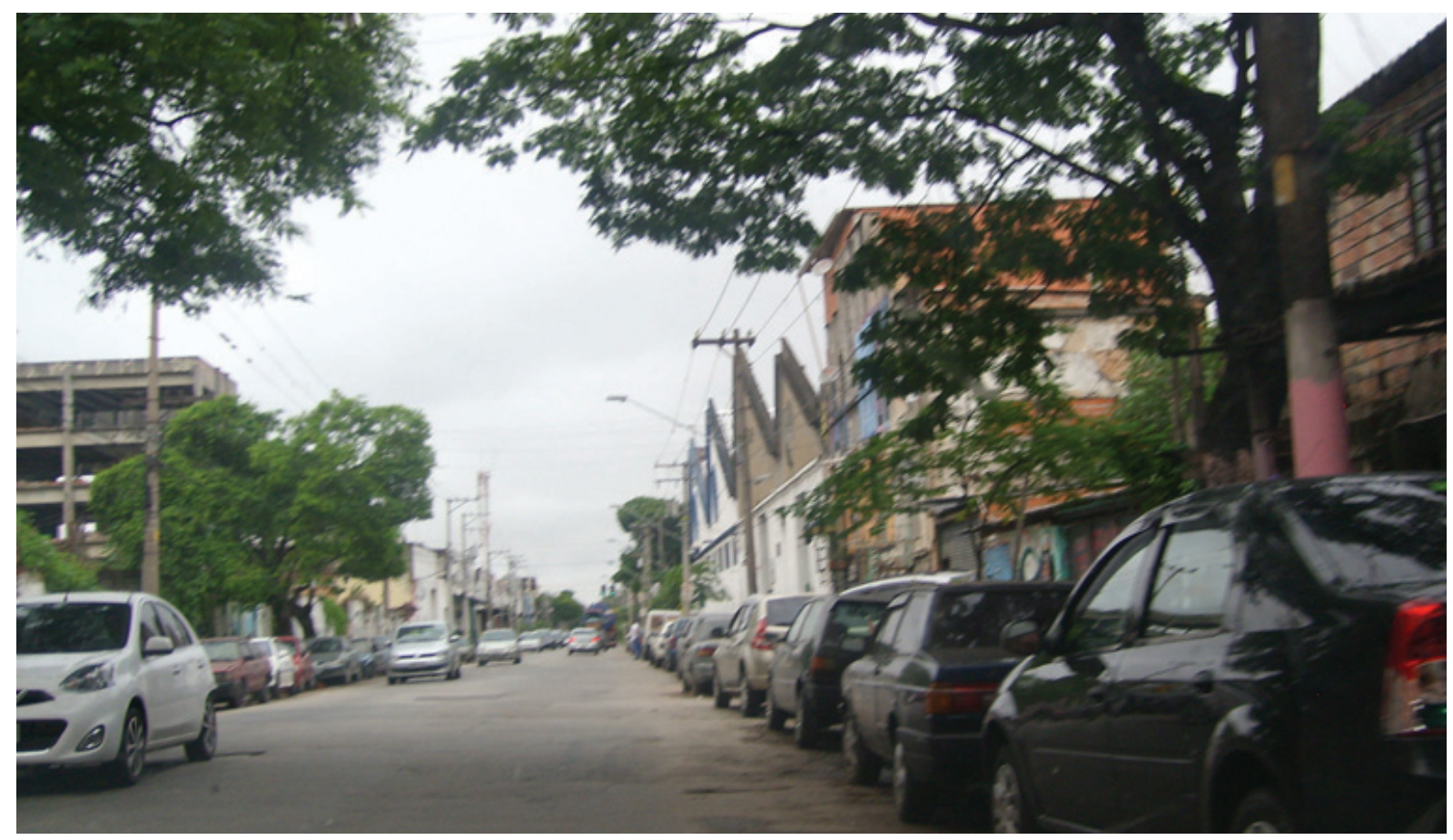

Figura 12 - Vista geral da área de interesse. A direita o edifício antigamente ocupado como favela e à direita a favela Tamanduateí. Fonte: Próprio autor, 2015. 


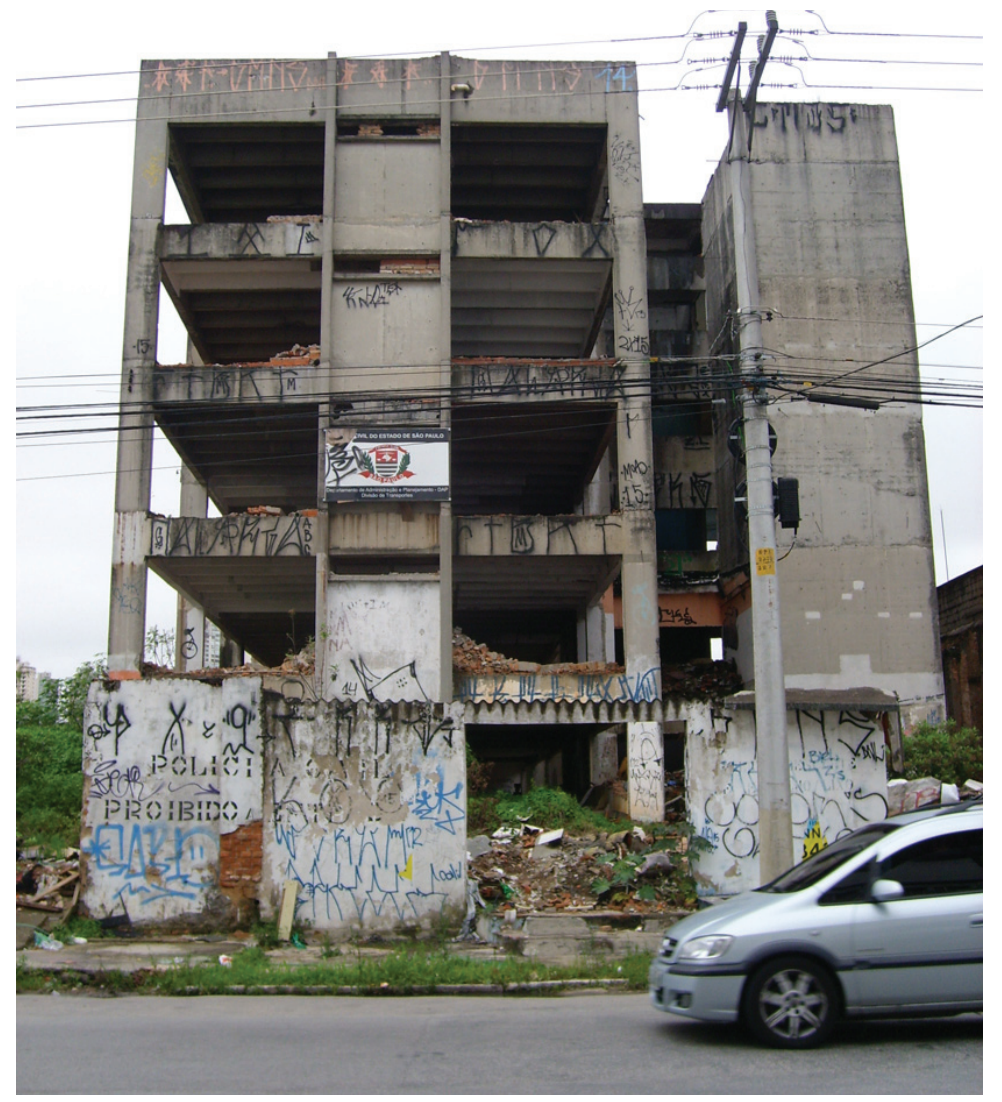

Figura 13 - Estrutura do prédio da Polícia Civil aonde localizava-se a Favela Presidente Wilson II Fonte: Próprio autor, 2015.
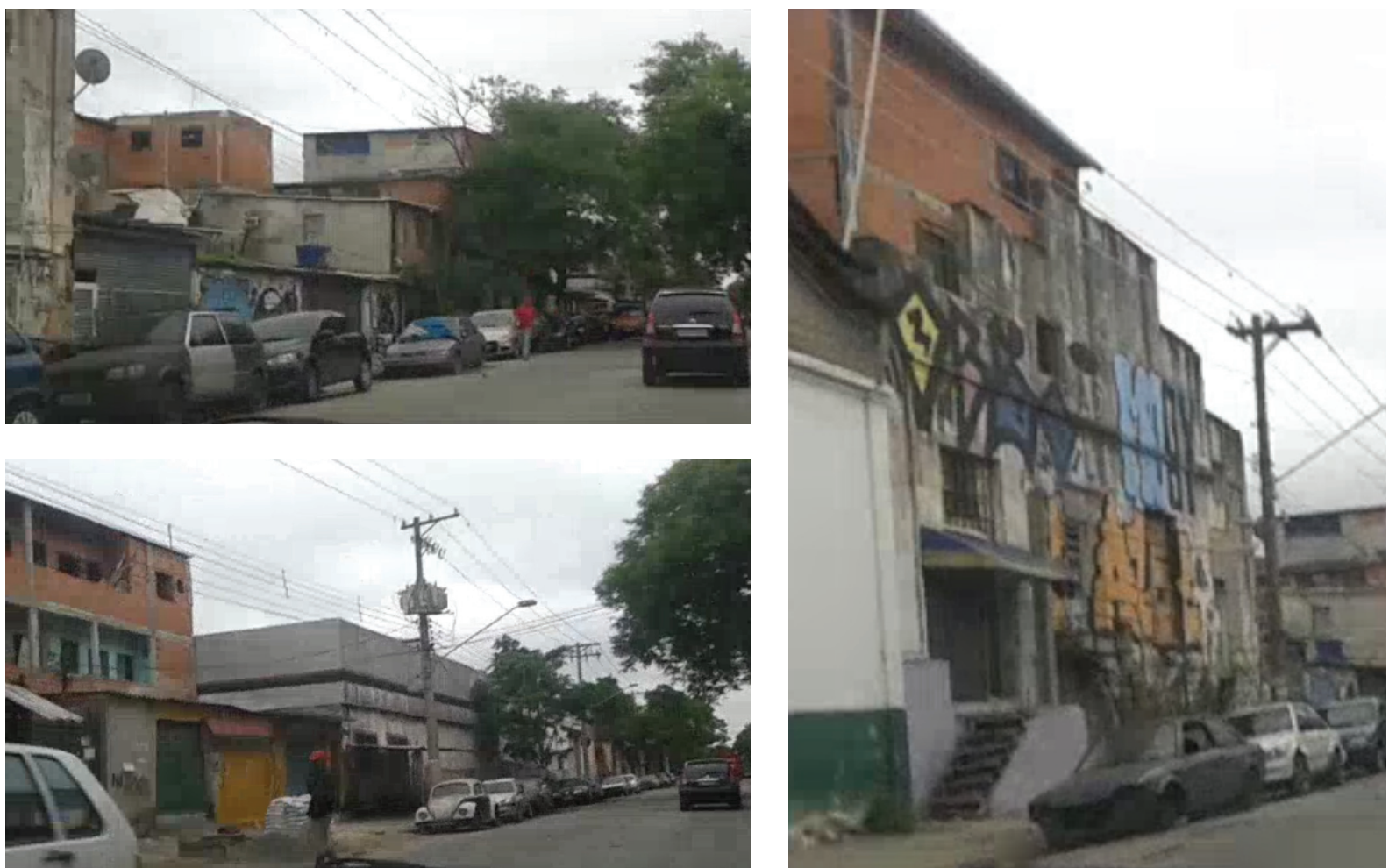

Figura 14 - Identificação da Favela Tamanduateí. Fonte: Próprio autor, 2015. 
O objetivo deste trabalho é entender como podem ser tratadas estas áreas de forma que possamos devolvê-las à cidade sem nenhum dano colateral para sua população. Para isto, não se pode simplesmente transformar as áreas contaminadas em parques e fazer a sua remediação através da fitorremediação², e iniciar uma descontaminação da área que possibilite a implantação de empreendimentos habitacionais no local.

O problema da ocupação irregular é maior do que as questões ambientais criadas pelo homem através das ligações irregulares, mas também abarca a problemática de degradação do território construído como um todo, inclusive no que diz respeito à salubridade do local. Este é um problema para além dos padrões estéticos, do valor venal do território, da falta de cuidado e de sentimento de pertencimento de alguns conglomerados como as favelas, principalmente para as mais recentes onde os moradores não possuem áreas de descarte regular, lançando produtos de uso cotidiano em locais pouco indicados como o córrego ou o próprio solo do local ocupado.

\begin{tabular}{|lll|}
\hline Efeitos da contaminação por metais pesados nos seres humanos \\
\hline Metal pesado & Onde é encontrado & Efeitos \\
\hline Mercúrio & Produtos farmacêuticos & Distúrbios renais \\
& Lâmpadas fluorescentes & Lesões neurológicas \\
& Interruptores & Efeitos mutagênicos \\
& Pilhas e baterias & Alterações do metabolismo \\
& Tintas & Deficiência nos órgăos sensoriais \\
& Fungicidas & Irritabilidade \\
& Termômetros & Insônia \\
& & Problemas renais \\
& & Cegueira, surdez \\
\hline Cádmio & Baterias e pilhas & Morte \\
& Plásticos & Dores reumáticas \\
& Pigmentos & Ostúrbios metabólicos \\
& Papéis & Disfunção renal \\
\hline Chumbo & Tintas & Perda de memória \\
Impermeabilizantes & Dor de cabeça \\
Cerâmica & Anemia \\
& Vidro & Paralisia \\
Inseticidas & \\
Baterias & \\
\hline
\end{tabular}

Este tipo de descarte pode trazer inúmeros problemas, uma vez que produtos tão aparentemente inofensivos como um celular ou uma pilha trazem consigo materiais altamente prejudiciais à saúde como pode ser identificado no quadro da cartilha de lixo do Ministério do Meio Ambiente $^{3}$ ao lado.

Quadro 1 - Efeitos de alguns metais pesados no metabolismo humano. Fonte: MMA apud IPT e Cempre 1996

\footnotetext{
${ }^{2}$ A fitorremediação trata o problema da contaminação através da plantação de espécies específicas de plantas capazes de absorver a água e os contaminantes do solo retendo-os na sua estrutura.

3 Diponível em: http://www.mma.gov.br/estruturas/sedr_proecotur/_publicacao/140_ publicacao09062009031109.pdf
} 


\section{POSSIBILIDADES PARA REMEDIAÇÃO}

Segundo o Manual de Áreas Contaminadas da CETESB existem atualmente duas formas de remediar uma área contaminada:

"medidas de contenção ou isolamento da contaminação e medidas para o tratamento dos meios contaminados, visando à eliminação ou redução dos níveis de contaminação a níveis aceitáveis ou previamente definidos." (CETESB 2001)

Dado um cenário ideal, seria possível afirmar que as áreas contaminadas deveriam ser saneadas completamente, principalmente quando os níveis de contaminação alcançam os níveis de aquíferos. Porém, enormes são as dificuldades políticas, sociais e econômicas que tais ações trariam, principalmente em um panorama como o atual em que as medidas de remediação requerem que as áreas contaminadas sejam compatíveis com os níveis máximos aceitáveis para a população, mas elas não são cumpridas plenamente pelos proprietários particulares e muito menos pelo poder público, sendo o motivo principal o alto custo da daquela.

É importante neste sentido identificar o potencial uso para os terrenos afetados, uma vez que os níveis aceitáveis de contaminantes no solo variam do tipo de uso que será dado para este. Este ponto pode não só restringir o uso do local como também definir o tipo de remediação que será dada. É fundamental que o uso destinado para tal território impeça que a rota de contaminação se feche.

Existem hoje quatro tipos de tecnologias de remediação: a remediação biológica; a físico-químico; a solidificação/estabilização e a remediação térmica. Este tipo de tecnologia não pode ser confundido com as medidas de engenharia, uma vez que estas tem a finalidade de interromper a exposição dos receptores (IPT 2014).

Dentre estes quatro tipos de tecnologias são utilizadas hoje 33 variações destas tecnologias que variam desde sua aplicação (in situ ou ex situ), passando pelo meio a ser tratado até os tipos de processos que usam, como pode ser verificado no Quadro 2 a seguir. 


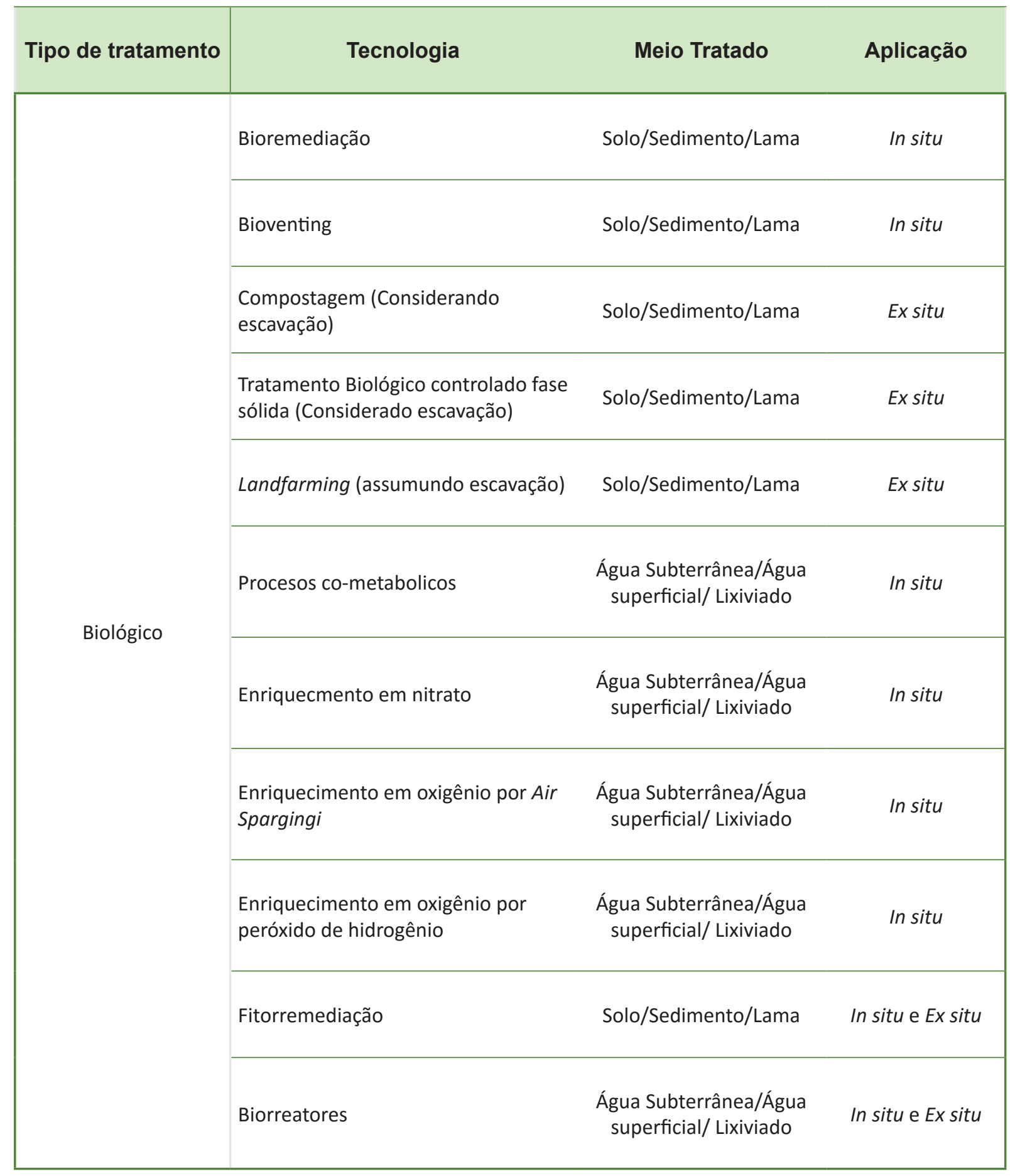




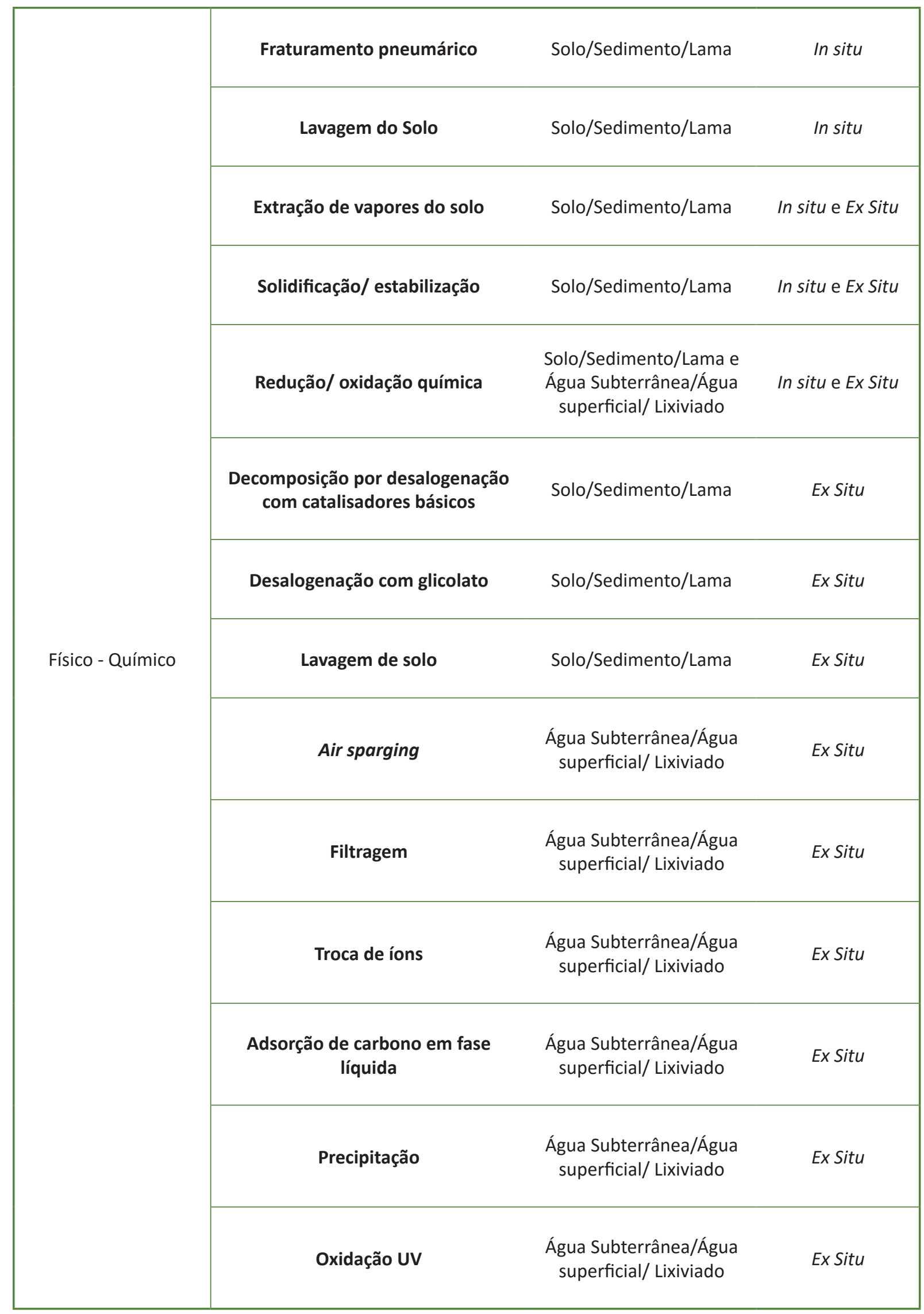




\begin{tabular}{|c|c|c|c|}
\hline \multirow{6}{*}{ Térmico } & $\begin{array}{c}\text { Extração de vapor do solo forçada } \\
\text { termicamente }\end{array}$ & Solo/Sedimento/Lama & In situ \\
\hline & $\begin{array}{l}\text { Dessorção térmica a alta } \\
\text { temperatura }\end{array}$ & Solo/Sedimento/Lama & Ex situ \\
\hline & Incineração & Solo/Sedimento/Lama & Ex situ \\
\hline & Descontaminação com gás quente & Solo/Sedimento/Lama & Ex situ \\
\hline & Pisólise & Solo/Sedimento/Lama & Ex situ \\
\hline & Vitrificação & Solo/Sedimento/Lama & In situ e Ex situ \\
\hline \multirow[b]{2}{*}{ Outros } & Escavação e disposição & Solo/Sedimento/Lama & In situ e Ex situ \\
\hline & Atenuação natural & $\begin{array}{l}\text { Solo/Sedimento/Lama e } \\
\text { Água Subterrânea/Água } \\
\text { superficial/ Lixiviado }\end{array}$ & In situ \\
\hline
\end{tabular}

Quadro 2 - Tipos de tratamento para remediação do solo contaminado.

Fonte: Adaptado IPT $2014^{4}$

A definição de qual tecnologia será utilizada depende de vários fatores entre eles o meio físico que será tratado e todos os seus parâmetros geotécnicos e as características físico-químicas dos contaminantes em questão.

${ }^{4}$ Disponível em <https://www.google.com.br/url?sa=t\&rct=j\&q=\&esrc=s\&source=web\&cd=1\&c ad=rja\&uact=8\&ved=0CCAQFjAAahUKEwio_vGLqYHJAhXDiZAKHTiqAGc\&url=http\%3A\%2F \%2Fwww.ipt.br\%2Fdownload.php\%3Ffilename\%3D1159-Guia__Gerenciamento_de_Areas_ Contaminadas_1a_edicao_revisada.pdf\&usg=AFQjCNEoxX-vduJ1jNUXhxTC3_4ryl-3nA\&sig2=X sPUaTzyrlkT3NbXjxDyfQ\&bvm=bv.106923889,d.Y2l> 


\section{CONSIDERAÇÕES FINAIS}

As questões relacionadas ao meio ambiente são por vezes tratadas de maneira independente do ambiente construído pelo ser humano, que, ressalta-se também é um ser natural, e portanto, sofre igualmente com os danos causados ao meio ambiente.

Muitas vezes a falta de planejamento e de uma compreensão holística das questões urbanas, como a própria configuração geológica, cultural e territorial do local, podem se agravar à medida que o tempo passa. Foi destacado no início do presente artigo como ocorreu a segregação do território industrial na cidade. Além disso, já é bastante conhecido para a área de planejamento urbano como a cidade de São Paulo localizase em um território desfavorável para sua ocupação, ocupando áreas de várzeas e encostas. Esta ocupação inadequada cria problemas não só de segurança por conta dos riscos de inundação e desabamento, mas também o risco à saúde e ao meio ambiente. As áreas descritas neste artigo têm como agravante a sua proximidade com o córrego e o seu lençol freático muito próximo à superfície, o que facilita o transporte dos contaminantes pelo solo, podendo aumentar rapidamente a pluma de contaminação afetando terrenos sem contaminação e a própria água que, por vezes, é utilizada pelas comunidades próximas, como no caso de favelas próximas a córregos e nascentes.

A constante negligência com os territórios ociosos traz consigo problemas muitas vezes piores que os trazidos pelas ocupações e ligações irregulares, as quais podem ser fonte de contaminação. A utilização de um terreno contaminado sem um cuidado específico pode trazer sérios problemas à saúde. Ressalta-se que por vezes os ocupantes criam animais e possuem plantações para consumo próprio, sendo assim, o risco de contaminação nem sempre se dá por contato dérmico, mas também por ingestão de produtos que possuem algum tipo de contaminante.

Os danos à saúde e a quantidade de população já contaminada nem sempre conseguem ser detectados em comparação com o tempo que o organismo leva para combater os materiais indesejados, além de nem sempre ser elaborado um estudo aprofundado capaz de apontar o nexo causal entre a doença e a região habitada. A rotatividade das famílias, principalmente nestas áreas mais vulneráveis e irregulares não auxilia os estudos de contaminação, uma vez que os problemas derivados da contaminação podem ser apresentados anos após a mudança de moradia para uma outra região. 
Contudo, hoje já existem várias formas de remediação do solo. As autoridades locais, entendendo a dificuldade na remediação completa do solo, solicitam que a remediação alcance níveis compatíveis com os valores de contaminantes que o ser humano é capaz de suportar. Para tanto, o nível de contaminantes deve ser compatível com a utilização que será dada ao local. O problema maior no que diz respeito à descontaminação das áreas não é a impossibilidade de baixar os níveis de contaminantes, mas sim o custo que as técnicas de remediação demandam. Diante deste problema as autoridades em países que lidam com os passivos do seu período industrial criam subsídios para auxiliar na remediação do solo, seja através de pagamentos prévios ou mensais devidos pelas empresas poluidoras para o governo, criando-se assim um fundo para a remediação.

Importante destacar que no Brasil o tratamento destas áreas é muito recente e a falta de apoio político para instituir a cobrança de taxas para indústrias como em outros países, as quais poderiam ser posteriormente revertidas para a descontaminação de áreas, impede grandes melhorias nos terrenos públicos contaminados.

Embora o panorama nacional não seja tão positivo quanto o internacional, atualmente existem estudos, técnicas para tratar as áreas contaminadas, porém, ainda há muito a se aprender com os países mais avançados nessa questão.

\section{REFERÊNCIAS BIBLIOGRÁFICAS}

ATSDR, Evaluacion de Riesgos en Salud por la Exposicion a Resíduos Peligrosos, Departamento de Salud Humana y Servícios de los E.E.U.U. Servicio de Salud Pública, Agencia para las Sustancias Tóxicas y el Registro de Enfermedades, Atlanta Georgia, 1992

BARROS, Luzia Helena dos Santos. Requalificação dos aterros desativados (brownfields) no Município de São Paulo: Parques (greenfields) Raposo Tavares e Jardim Primavera. 2011. Tese (Doutorado em Paisagem e Ambiente) - Faculdade de Arquitetura e Urbanismo, Universidade de São Paulo, São Paulo, 2011. Disponível em:<http://www.teses.usp.br/teses/disponiveis/16/16135/tde-31052012-103256/>. Acesso em: 2015-11-13. 
Brasil. Secretaria de Estado da Saúde São Paulo. Centro de Vigilância Epidemiológica. Manual de Vigilância em Saúde Ambiental para Ações em Vigilância em Saúde relacionada à População Exposta a Solo Contaminado - Secretaria de Estado da Saúde, Centro de Vigilância Epidemiologica, São Paulo, 2010

CUNHA, Rodrigo César de Araújo. Avaliação de Risco em Áreas Contaminadas por Fontes Industriais Desativadas - Estudo de Caso. 1997. Tese (Doutorado em Recursos Minerais e Hidrogeologia) - Instituto de Geociências, Universidade de São Paulo, São Paulo, 1997. Disponível em: <http://www.teses.usp.br/teses/ disponiveis/44/44133/tde-02042014-150225/>. Acesso em: 2015-07-05.

IPT, Gerenciamento de Áreas Contaminadas, $1^{\text {a }}$ edição revisada, 2014 Disponível em: https://www.google.com.br/url?sa=t\&rct=j\&q=\&esrc=s\&source=web\&cd=1\&cad=rja\&uact =8\&ved=0CCAQFjAAahUKEwio_vGLqYHJAhXDiZAKHTiqAGc\&url=http\%3A\%2F\%2Fw ww.ipt.br\%2Fdownload.php\%3Ffilename\%3D1159-Guia__Gerenciamento_de_Areas_ Contaminadas_1a_edicao_revisada.pdf\&usg=AFQjCNEoxX-vduJ1jNUXhxTC3_4ryl3nA\&sig2=XsPUaTzyrlkT3NbXjxDyfQ\&bvm=bv.106923889,d.Y2I.

CETESB, Guia para Avaliação do Potencial de Contaminação em Imóveis. Disponível em: http://www.cetesb.sp.gov.br/userfiles/file/tecnologia-ambiental/guia_aval_pot_ con_imoveis.pdf. Acesso em: 2014-03-11

CETESB, Manual de gerenciamento de áreas contaminadas. Disponível em:

$<$ http://www.cetesb.sp.gov.br/areas-contaminadas/manual-de-gerenciamento-deACs/7->. Acesso em: 2014-03-11

Gestão Urbana, Texto da Minuta do Projeto de Lei, Disponível em http://gestaourbana. prefeitura.sp.gov.br/arquivos-pl-oucbt/. Acessado em: 2015-10-26.

GÜNTHER, W. M. R. Contaminação ambiental por disposição inadequada de resíduos industriais contendo metais pesados: estudo de caso: estudo de caso. 1998. Tese (Doutorado em Saúde Ambiental) - Faculdade de Saúde Pública, Universidade de São Paulo, São Paulo, 1998. Disponível em: <http://www.teses.usp.br/teses/ disponiveis/6/6134/tde-29092014-111117/>. Acesso em: 2015-07-05.

GÜNTHER, W. M. R. São Paulo em Perspectiva, Áreas contaminadas no contexto da gestão urbana, v.20, n.2, p. 105-117, abr./jun. 2006. 
MARTINE, George (Org.). População Meio Ambiente e Desenvolvimento: Verdades e Contradições. Campinas, SP, Editora Unicamp, 1993.

MEADOWS, Donella H. Limites do Crescimento: AAtualização de 30 anos / Donella Meadows, Jorgen Rangers, Dennis Meadows. - Rio de Janeiro: Qualitymark, 2007.

Ministério do Meio Ambiente, Cartilha Lixo: um grande problema no mundo moderno. Disponível em: http://www.mma.gov.br/estruturas/sedr_proecotur/_publicacao/140_ publicacao09062009031109.pdf Acesso em: 2015-09-11

MORINAGA, Carlos Minoru. Recuperação de áreas contaminadas: um novo desafio para projetos paisagísticos. 2007. Dissertação (Mestrado em Paisagem e Ambiente) Faculdade de Arquitetura e Urbanismo, Universidade de São Paulo, São Paulo, 2007. Disponível em: <http://www.teses.usp.br/teses/disponiveis/16/16135/tde-19092007113720/>. Acesso em: 2014-04-14.

SANCHES, Patrícia Mara. De áreas degradadas a espaços vegetados: potencialidades de áreas vazias, abandonadas e subutilizadas como parte da infraestrutura verde urbana. 2011. Dissertação (Mestrado em Paisagem e Ambiente) - Faculdade de Arquitetura e Urbanismo, Universidade de São Paulo, São Paulo, 2011. Disponível em: <http://www.teses.usp.br/teses/disponiveis/16/16135/tde-05122011-100405/>. Acesso em: 2014-04-17.

SANCHES, Luiz Enrique. Desengenharia: o passivo ambiental na desativação de empreendimentos industriais. Ed. São Paulo: Editora Universidade de São Paulo, 2001.

SANTOS, Fábio Alexandre dos. Domando as águas: salubridade e ocupação do espaço na cidade de São Paulo, 1875-1930. Tese (Doutorado em Economia Aplicada) - Instituto de Economia, Universidade Estadual de Campinas, Campinas, 2006. Disponível em: <http://www.bibliotecadigital.unicamp.br/document/?code=vtls000395048>. Acesso em: 2015-11-02.

Secretaria do Verde e do Meio Ambiente - SMVA. Planejamento Urbano Integrado e Participação Social na Recuperação e Reintegração de áreas degradadas: Lições aprendidas no Projeto Piloto INTEGRATION na região Mooca-Vila Carioca. $1^{\text {a }}$ ed. São Paulo, 2012. 
Secretaria do Verde e do Meio Ambiente - SMVA. Manual: Promovendo a comunicação e a participação social e institucional no planejamento urbano. $1^{\text {a }}$ ed. São Paulo, 2012.

URBAL, http://www.urbal-integration.eu/index.php?id=home\&L=2

RIMA, http://issuu.com/svmasp/docs/rima_operacaoconsorciada_mooca-vila 